10

\title{
Получение флуоресцентных композитных материалов на основе графитоподобного нитрида углерода
}

\author{
(С А.Б. Богомолов ${ }^{1,2}$, С.А. Кулаков ${ }^{2}$, П.В. Зинин ${ }^{1}$, В.А. Кутвицкий ${ }^{2}$, М.Ф. Булатов ${ }^{1}$ \\ ${ }^{1}$ Научно-технологический центр уникального приборостроения РАН, \\ 117342 Москва, Россия \\ ${ }^{2}$ Российский технологический университет, \\ 119571 Москва, Россия \\ Te-mail: Bogomolov1395@gmail.com \\ Поступила в редакцию 15.01.2020 г. \\ В окончательной редакции 23.03.2020 г. \\ Принята к публикации 28.03.2020 г.
}

На основе графитоподобного нитрида углерода $\left(g-\mathrm{C}_{3} \mathrm{~N}_{4}\right)$ методом термического разложения меламина в присутствии наночастиц оксида алюминия, оксида титана и оксида кремния получен высокофлуоресцентный композитный порошок. Изучены флуоресцентные свойства композитных наночастиц с источником возбуждения, имеющим длину волны $532 \mathrm{~nm}$. Относительный квантовый выход полученного материала составил $62 \%$.

Ключевые слова: флуоресцентный материал, композитный материал на основе $g-\mathrm{C}_{3} \mathrm{~N}_{4}$, флюоресценция, относительный квантовый выход.

DOI: $10.21883 /$ OS.2020.07.49562.109-20

\section{Введение}

Графитоподобные материалы из нитрида углерода используются в качестве катализаторов для расщепления воды сравнительно недавно [1], несмотря на то, что методы получения графитоподобных материалов известны давно (обзор методов можно посмотреть в [2]). Термин „графитоподобные материалы из нитрида углерода“ включает в себя широкий спектр материалов с различной микроструктурой от аморфной до нанокристаллов и нанопористых материалов [3]. Многие из описанных в литературе соединений имеют соотношение углерода к азоту $3: 4$, благодаря чему и получили название $g-\mathrm{C}_{3} \mathrm{~N}_{4}$. Как правило, по своей структуре они представляют собой агрегаты, состоящие из графитоподобных $\mathrm{C}-\mathrm{N}$ слоев, находящихся в состоянии $s p^{2}$-гибридизации.

Применение спектроскопии комбинационного рассеяния с возбуждением в инфракрасном (ИК) диапазоне оказалось очень эффективным в исследовании алмазоподобных состояний и графитоподобных фаз [4] из $\mathrm{B}-\mathrm{C}-\mathrm{N}$-треугольника [5]. В последнее время мы проводили исследование химических связей графитоподных фаз $g-\mathrm{C}_{3} \mathrm{~N}_{4}$ с использованием комбинационного рассеяния в ИК диапазоне [6]. Спектр комбинационного рассеяния $g-\mathrm{C}_{3} \mathrm{~N}_{4}$ в ИК диапазоне значительно отличается от спектра в видимом диапазоне. В ИК спектре были обнаружены две сильные линии 691 и $988 \mathrm{~cm}^{-1}$, которые приписываются различным типам дышащих мод $s$-триазиновых колец. Наши результаты, полученные в ИК диапазоне для $g-\mathrm{C}_{3} \mathrm{~N}_{4}$, были подтверждены в работе [7]. Мы планируем использовать этот метод для исследования графитоподобных и новых фаз $\mathrm{C}_{3} \mathrm{~N}_{4}$, а также для наблюдения поведения связей, находящихся в состояниях $s p^{2}$ - и $s p^{3}$-гибридизации, в условиях высоких давлений.

Сильная флуоресценции под действием лазерного излучения графитоподобных модификаций $\mathrm{C}_{3} \mathrm{~N}_{4}$ была обнаружена при исследовании комбинационого рассеяния света [8]. Для снижения нежелательного влияния флуоресценции $g-\mathrm{C}_{3} \mathrm{~N}_{4}$ при измерениях спектра комбинационного рассеяния были использованы ультрафиолетовые лазеры и инфракрасные лазеры [8]. Первые же количественные измерения квантовых точек нитрида углерода $(\mathrm{CN})$ показали, что они могут эффективно использоваться как флуоресцентные метки с квантовым выходом 11\% [9].

Исследования, проведённые в Научно-технологическом центре уникального приборостроения РАН (НТЦ УП РАН), показали, что квантовый выход флуоресценции полых $\mathrm{C}_{3} \mathrm{~N}_{4}$-наночастиц сферической формы $(s$ $\left.\mathrm{C}_{3} \mathrm{~N}_{4}\right)$ на два порядка выше квантового выхода интенсивности флуоресценции неупорядоченных графитоподобных частиц нитрида углерода $\left(g-\mathrm{C}_{3} \mathrm{~N}_{4}\right)[10]$. Природа рекордных значений квантового выхода флуоресценции, достигающего $32 \%$ при возбуждении лазером с длиной волны $532 \mathrm{~nm}$ и $38 \%$ - при возбуждении лазером с длиной волны $633 \mathrm{~nm}$, неизвестна и объяснялась резонансным рассеянием света сферическими наночастицами нитрида углерода [10].

Существует много методов получения $g-\mathrm{C}_{3} \mathrm{H}_{4}$, начиная от зрелищной реакции разложения тиоцианата ртути, заканчивая методом лазерного осаждения с фемтосекундным импульсом [11]. Наиболее дешевой является методика получения из мочевины, но после синтеза 
требуется тщательная очистка от примесей [12]. Хорошо зарекомендовала себя методика получения сферических частиц $g-\mathrm{C}_{3} \mathrm{~N}_{4}$ путем реакции цианурхлорида с нитридом лития [13]. Но самым распространенным и экологичным методом является элиминирование меламина при температурах от 400 до $600^{\circ} \mathrm{C}$ [14]. Очень перспективным на данный момент является метод получения соединения нитрида углерода с благородными металлами, на данный момент уже получены образцы с платиной, но не изучены их флуоресцентные свойства [15].

Целью настоящего исследования является получение композитных наночастиц на основе инертного оксида и графитоподобного нитрида углерода, обладающих интенсивной люминесценцией в видимом диапазоне. Полученный композит - новый материал для оптики, так как может использоваться в роли генератора излучения и дать основу для создания флуоресцентных зондов в биологии и медицине [16].

\section{Синтез}

Для получения $g-\mathrm{C}_{3} \mathrm{~N}_{4}$ был выбран метод термического разложения меламина $\left(\mathrm{C}_{3} \mathrm{~N}_{6} \mathrm{H}_{6}\right)$, основными преимуществами которого является экологичность, низкая стоимость, безопасность и одностадийность. В данном случае композитный материал на основе нитрида углерода получали следующем образом: смешивалась навеска высушенного меламина (чистота 99.7\%) с оксидом в соотношении $1: 3$, данная смесь перетиралась в агатовой ступке. В качестве инертных оксидов использовались сферические наночастицы оксида кремния $\left(\mathrm{SiO}_{2}\right)$, имеющие размер 5-15 nm, частицы оксида титана $\left(\mathrm{TiO}_{2}\right)$ с размером 50-150 nm и мелкодисперсный порошок оксида алюминия $\left(\mathrm{Al}_{2} \mathrm{O}_{3}\right)$.

Смесь помещалась в глиноземный тигель и устанавливалась в муфельную печь, где происходило разложение при температуре $500^{\circ} \mathrm{C}$ в течение 3 часов. В процессе реакции выделялся аммиак:

$$
\mathrm{C}_{3} \mathrm{~N}_{6} \mathrm{H}_{6} \stackrel{500^{\circ \mathrm{C}}}{\longrightarrow} g-\mathrm{C}_{3} \mathrm{~N}_{4}+2 \mathrm{NH}_{3} \uparrow .
$$

Во время синтеза происходит элиминирование меламина с отщеплением аммиака, в результате синтеза формируется полимерная пленка, которая частично обволакивает добавленные частицы инертных оксидов. В случае увеличения количества меламина в реакционной зоне формируется крупный молекулярный кластер, представляющий собой хрупкий матовый полимер, повторяющий форму тигля.

С целью подтверждения инертности полученной структуры была проведена серия экспериментов, в которых нитрид углерода помещался в различные агрессивные среды: $\mathrm{HF}$ (40 об.\%), $\mathrm{NaOH}$ (30 об.\%), $\mathrm{H}_{2} \mathrm{SO}_{4}$ (40 об.\%), $\mathrm{C}_{2} \mathrm{H}_{5} \mathrm{OH}$ (98 об.\%). Во всех этих случаях не было обнаружено никаких признаков реакции, вследствие чего можно утверждать, что благодаря своей графитоподобной структуре нитрид углерода инертен.

\section{Измерение квантового выхода флуоресценции}

Для исследования флуоресценции и комбинационного рассеяния света была разработана специализированная установка (рис. 1), в которой флуоресценция возбуждается двумя лазерами, работающими на длинах волн 405 (Oxxius, LBX-405, Франция) и $532 \mathrm{~nm}$ (Oxxius, LCX-532L, Франция).

Спектры флуоресценции измерялись при помощи спектрометра, состоящего из монохроматора (Solar Laser Systems M266, Белорусия) с ПЗС-детектором (прибор с зарядовой связью, U2C-16Н10426, Япония). Сканирование происходило в диапазоне 400-850 nm с дифракционной решеткой 600 lines $/ \mathrm{mm}$. В установке также использовался отражатель света на длине волны $532 \mathrm{~nm}$

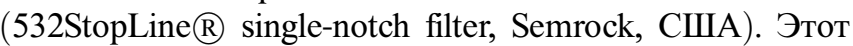
фильтр отражает лазерный лучи на указанной частоте, пропуская только рассеянный свет на спектрометр. Изображение источника и юстировка лазерного луча осуществляются с помощью оптической системы, состоящей из видеокамеры (Imaging Source DFK 22AUC03, $644 \times 484$ pixels, Германия), источника освещения, объектива $(50 \times$, Plan Apo, ULWD, NA $=0.42, \mathrm{WD}=22.5 \mathrm{~mm}$, Edmund Optics, CША), двух линз и двух делителей световых пучков.

Относительный квантовый выход определялся методом сравнения с образцом, имеющим установленный абсолютный квантовый выход. В качестве такого образца был использован родамин В, так как его максимум абсорбции приходится на оптимальный диапазон длин волн от 530 до $560 \mathrm{~nm}$. Водный 0.01\%-раствор родамина В имеет относительный квантовый выход $31 \%$ [17]. Для измерения флуоресценции раствора родамина В использовалась кварцевая кювета с пропускающим диапазоном 190-2500 $\mathrm{nm}$.

Относительный квантовый выход рассчитывался по формуле

$$
Q_{\mathrm{y}}=Q_{\mathrm{et}} \frac{S_{\text {dye }}}{S_{\mathrm{et}}},
$$

где $Q_{\mathrm{et}}=0.31-$ абсолютный квантовый выход, $S_{\text {dye }}$ и $S_{\text {et }}$ - площади под спектрами флуоресценции. В нашем эксперименте относительный квантовый выход композитного наиболее флуоресцентного материала составил $62 \%$.

\section{Результаты и обсуждения}

На рис. 2 представлены спектры флуоресценции образцов при возбуждении лазером с длиной волны $532 \mathrm{~nm}$. Результаты измерений квантового выхода приведены в таблице. Наибольшее значение относительного квантового выхода было обнаружено у $g-\mathrm{C}_{3} \mathrm{~N}_{4} / \mathrm{Al}_{2} \mathrm{O}_{3}$ и составило порядка $62 \%$ при возбуждении волной с длиной $532 \mathrm{~nm}$, также очень высокий уровень имеет $g-\mathrm{C}_{3} \mathrm{~N}_{4} / \mathrm{TiO}_{2}$. Мы предполагаем, что данный эффект 


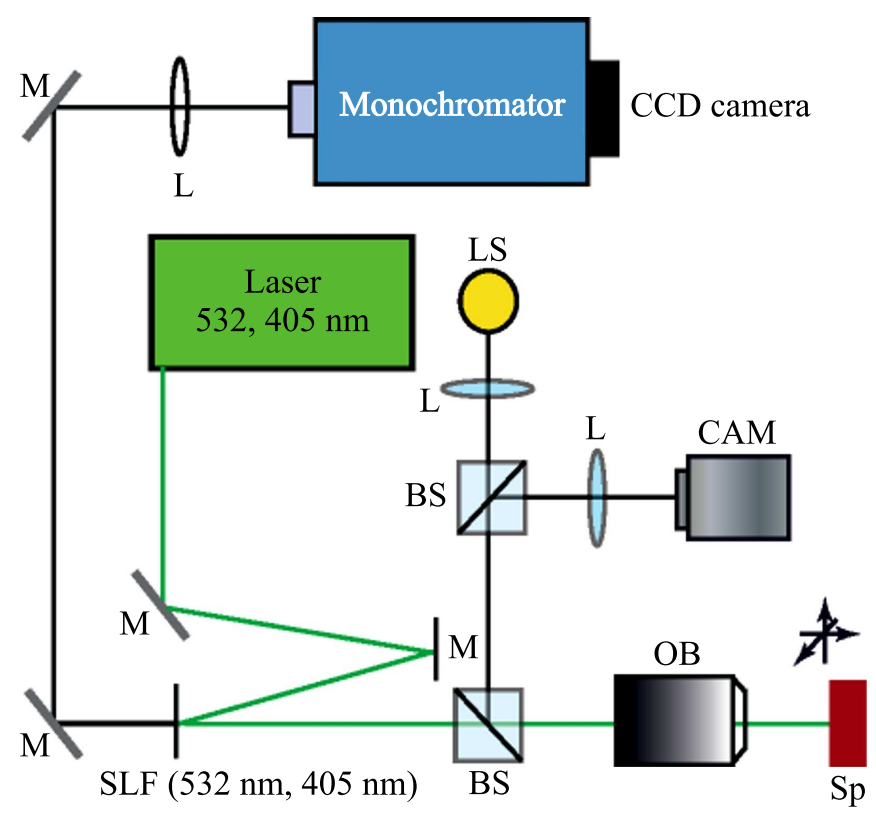

Рис. 1. Схема установки для измерения флуоресценции нанокомпозитных смесей $g-\mathrm{C}_{3} \mathrm{~N}_{4}$ : BS - светоделитель, САМ видеокамера, M - зеркало, L - линза, LS - источник света, SLF - отражатель света на длине волны 532 или $405 \mathrm{~nm}$, $\mathrm{Sp}$ - образец.

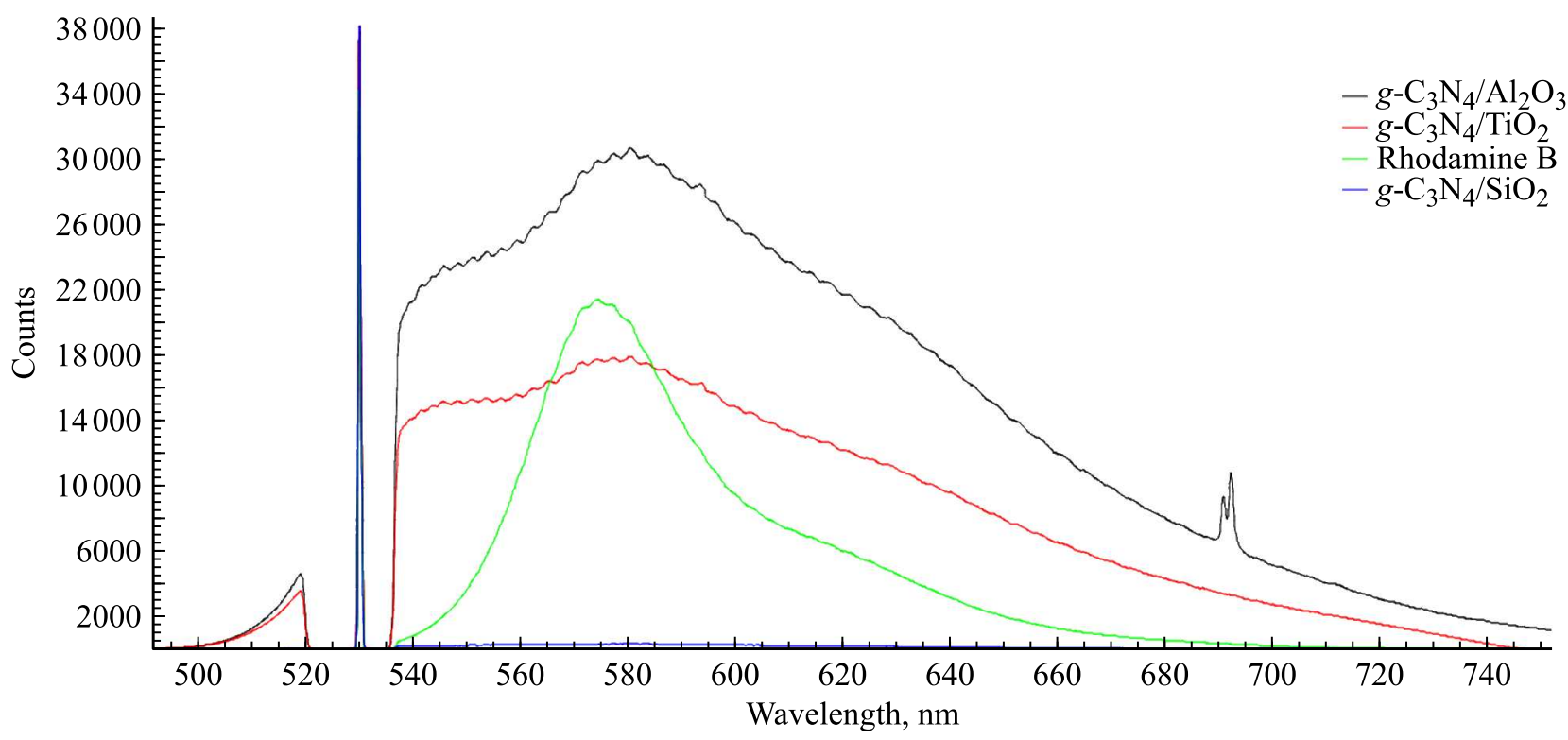

Рис. 2. Спектры флуоресценции образцов при возбуждении лазером с длиной волны $532 \mathrm{~nm}$.

связан плазмонным резонансом [18]. Интенсивность люминесценции в антистоксовом пространстве составляет $15 \%$ от площади спектра в стоксовом пространстве. Максимум интенсивности флуоресценции приходится на длину волны $580 \mathrm{~nm}$. Самая слабая флуоресценция наблюдается для $\mathrm{C}_{3} \mathrm{~N}_{4} / \mathrm{SiO}_{2}$ (рис. 2). Полученные результаты значительно отличаются от описанных в 2015 г. [10]: так, квантовый выход $\mathrm{C}_{3} \mathrm{~N}_{4} / \mathrm{SiO}_{2}$ при возбуждении волной длины $532 \mathrm{~nm}$ составил $0.2 \%$, в то время как для сферических частиц, полученных в результате реакции цианурхлорида с нитридом лития, квантовый выход составил 32\%. У наиболее флуоресцентных образцов состава C3N4/A12O3 частицы обладают достаточно интенсивным излучением в антистоксовом пространстве. Интенсивность флуоресценции в антистоксовом пространстве составляет 15\% от площади спектра в стоксовом пространстве при возбуждении волной с длиной $532 \mathrm{~nm}$, данный результат также отличается в меньшую сторону, так как сферические частицы, полученные в 2015 г., имели 42\% от площади спектра в стоксовом про- 
Относительный квантовый выход полученных образцов

\begin{tabular}{l|c|c}
\hline \multicolumn{1}{c|}{ Образец } & Размер частиц & QY \\
\hline$g-\mathrm{C}_{3} \mathrm{~N}_{4} / \mathrm{Al}_{2} \mathrm{O}_{3}$ & $500-2000 \mathrm{~nm}$ & 0.62 \\
$g-\mathrm{C}_{3} \mathrm{~N}_{4} / \mathrm{TiO}_{2}$ & $50-150 \mathrm{~nm}$ & 0.56 \\
Родамин B & - & 0.31 \\
$g-\mathrm{C}_{3} \mathrm{~N}_{4} / \mathrm{SiO}_{2}$ & $5-15 \mathrm{~nm}$ & 0.02
\end{tabular}

странстве при возбуждении с длиной волны $633 \mathrm{~nm}$. Частицы $g-\mathrm{C}_{3} \mathrm{~N}_{4} / \mathrm{Al}_{2} \mathrm{O}_{3}$ обладают рекордным показателем интенсивности люминесценции, который определяется квантовым выходом в 62\%. Нам не известна природа усиления люминесценции в композитных наночастицах на графитоподобном нитриде углерода.

Усиление комбинационного рассеяние света или эффект гигантского комбинационного рассеяния впервые был обнаружен на пиридине, адсорбированном на шероховатой Ag-проволке. Гигантское комбинационное рассеяние обусловлено возбуждением поверхностных плазмон-поляритонов на границе раздела между металлом и диэлектриком [19]. Можно предположить, что аналогичный механизм действует и в случае флуоресценции металлических наночастиц.

\section{Выводы}

Успешно получен композитный флуоресцентный материал, обладающий аномально высоким уровнем флуоресценции. Наибольшее значение относительного квантового выхода было обнаружено у $g-\mathrm{C}_{3} \mathrm{~N}_{4} / \mathrm{Al}_{2} \mathrm{O}_{3}$ и составило порядка $62 \%$ при возбуждении волной с длиной $532 \mathrm{~nm}$, также очень высокий уровень имеет $g$ $\mathrm{C}_{3} \mathrm{~N}_{4} / \mathrm{TiO}_{2}$. Мы предполагаем, что данный эффект происходит из-за плазмонного резонанса [20]. Интенсивность люминесценции в антистоксовом пространстве составляет $15 \%$ от площади спектра в стоксовом пространстве. Материал с таким составом получен впервые, соответственно, впервые исследованы его флуоресцентные свойства.

Полученные композитные соединения термически и химически стабильны, что делает их отличными кандидатами для создания органических светодиодов и маркеров при исследованиях потоков [21] и создании флуоресцентных зондов.

\section{Благодарности}

Выражаем благодарность профессору университета Хьюстона (США) В.В. Хабашеску за обсуждение результатов работы. Эта работа выполнена на уникальной научной установки „Лазерный нагрев в алмазной наковальне“.

\section{Конфликт интересов}

Конфликт интересов отсутствует.

\section{Список литературы}

[1] Wang X., Maeda A., Thomas A., Akanabe K., Xin G., Carlsson J. // Nat. Mater. 2009. V. 8. N 1. P. 76-80.

[2] Thomas A., Fischer F., Goettma A. // J. Mater. Chem. The Royal Society of Chemistry, 2008. V. 18. N 41. P. 4893-4908.

[3] Dong G., Zhang Y., Pan Q., Qio Q. // J. Photochem. Photobiol. C Photochem. Rev. Elsevier B.V., 2014. V. 20. N 1. P. 33-50.

[4] Hubble H.W. Kudryashov V., Solozhenko V. // J. Raman Spectrosc. 2004. V. 35. N 10. P. 822-825.

[5] Ming L. Zinin P., Manghnani M., Carvalho M., Hogo T. // Microsc. Microanal. 2005. V. 11. N S2. P. 2028-2029.

[6] Znin P., Ming L., Sharma S., Khabasheskun V., Liu X., Acosta T. // Chem. Phys. Lett. 2009. V. 472. N 1-3. P. 69-73.

[7] McMillan P., Lees V., Qurico E., Montagnac E., Sella G., Bailei P., Cora M. // J. Solid State Chem. 2009. V. 182. N 10. P. 2670-2677.

[8] Zinin P., Ming L., Sharma S., Khabasheskun V., Liu X., Acosta T. // Chem. Phys. Lett. 2009. V. 472. N 1-3. P. 69-73.

[9] Liu S., Tian L., Wang L., Zhai Y., Sun J.P. // J. Mater. Chem. 2011. V. 21. N 32. P. 11726-11729.

[10] Zinin P.V., Ryabova A., Davydov V., Khabashesku V., Boritko V., Sharma S., Pomonova S., Loshev D. // Chem. Phys. Lett. Elsevier B.V., 2015. V. 633. P. 95-98.

[11] Kanasaki J., Kanasaki J., Tanimura E., Ohnishi K., Nasu H. // Phys. Rev. Lett. 2009. V. 102. N 8. P. 87402.

[12] Mohamed N.A., Nurul A., Javad L., Aznan F., Muhammad F., Muhammad N., Mohamad F., Amin N., Sharifah N., Mohd A. // Appl. Surf. Sci. 2019. V. 489. N 3. P. 92-100.

[13] Zimmerman J.L., John L., Williams R., Khabashesku V., Margrave J. // Nano Lett. 2001. V. 1, N 12. P. 731-734.

[14] Hatamie A., Marahel F., Sharifat A. // Talanta. Elsevier B.V. 2018. V. 176. P. 518-525.

[15] Akhmedov V.M., Melnikova N.E., Babayeva A.Z., Nurullayev G.G., Aliyeva Z.M. // Azerbaijan Chem. J. 2019. V. 1841. P. $6-14$.

[16] Рочева В., Шолина Н., Деревяшкин С., Генералова А., Нечаев А., Хоченков Д., Семчишен В., Хайдуков Е., Cтепанова E. // Альманах клинической медицины. 2016. V. 2. P. $647-653$.

[17] Magde D., Rojas G.E., Seybold P.G. // Photochem. Photobiol. 1999. V. 70. N 5. P. 737-744.

[18] Tonda S., Kumar S., Shanker V. // Mater. Res. Bull. 2016. V. 75. P. $51-58$.

[19] Liu W., Shen J., Chen H., Liu H., Yang Q., Nang X., Peng H. // J. Nanosci. Nanotechnol. 2019. V. 19. N 9. P. 5582-5590.

[20] Dahlman C., Agrawal A., Saller C., Corey A. // Chem. Mater. American Chemical Society, 2019. V. 31. N 2. P. 502-511.

[21] Барткус Г. // Интерэкспо Гео-Сибир. 2016. V. 1. Р. 73-79. 